\title{
Head Up Games: combining the best of both worlds by merging traditional and digital play
}

\author{
Iris Soute $\cdot$ Panos Markopoulos $\cdot$ Remco Magielse
}

Received: 4 March 2009/ Accepted: 16 July 2009/Published online: 17 December 2009

(c) The Author(s) 2009. This article is published with open access at Springerlink.com

\begin{abstract}
Current pervasive games are mostly locationaware applications, played on handheld computing devices. Considering pervasive games for children, it is argued that the interaction paradigm existing games support limits essential aspects of outdoor play like spontaneous social interaction, physical movement, and rich face-to-face communication. We present a new genre of pervasive games conceived to address this problem, that we call "Head Up Games" (HUGs) to underline that they liberate players from facing down to attend to screen-based interactions. The article discusses characteristics of HUG and relates them to existing genres of pervasive games. We present lessons learned during the design and evaluation of three HUG and chart future challenges.
\end{abstract}

Keywords Children Pervasive games $\cdot$ Social gaming

\section{Introduction}

The availability of context sensing and augmented reality technologies have lead to the emergence of pervasive games: "[a] genre in which traditional, real-world games are augmented with computing functionality, or, depending on the perspective, purely virtual computer entertainment

\footnotetext{
I. Soute $(\bowtie) \cdot$ P. Markopoulos · R. Magielse

Department of Industrial Design,

Eindhoven University of Technology,

P.O. Box 513, 5600 MB Eindhoven, The Netherlands

e-mail: i.a.c.soute@tue.nl

P. Markopoulos

e-mail: p.markopoulos@tue.nl

R. Magielse

e-mail: r.magielse@tue.nl
}

is brought back to the real world" [1]. As a concept "pervasive gaming' has been linked to numerous research fields [2], such as ambient intelligence, augmented/mixed reality, mobile computing, location-aware computing, virtual reality, and smart toys. The research reported below the concerns specifically outdoor pervasive games for children.

In an outdoor setting, 'pervasive' is typically assumed to equal 'location-based' and numerous such games are reported in literature. Well-known examples are Can You See Me Now [3, 4] and Catchbob! [5]. Can You See Me Now was developed partly as an artwork and partly as a research vehicle to test location-based technologies outside the safe environment of a laboratory; it is a catch game involving online players and players on the street who traverse an actual city chasing the (virtually present) online players. CatchBob! was designed to explore locationawareness in the context of mobile collaboration. In CatchBob! players, in groups of three, have to find a virtual object by surrounding the object with a triangle formed by each participant's position in real space.

The games mentioned and many others of this type are played with a GPS and/or Wi-Fi device, and use a small display (PDA or mobile phone) to show location and other game-related information. By targeting adult players in outdoor environments, this genre of games has brought about a novel, non-conventional pastime and experience. For children, however, outdoor play is a natural and traditional occupation and one that is essential for them; it has often been argued that play provides ample learning opportunities and is beneficial for a child's development $[6,7]$.

Current research literature is sparse when it comes to outdoor pervasive games for children. Well-known examples are Savannah [8] and Ambient Wood [9]. In Ambient Wood, children take a field trip in a wood that is 
augmented with mobile and fixed devices providing contextually relevant information. Each pair of children carries a PDA and a probe. In Savannah, children are equipped with PDA's with Wi-Fi and GPS. A virtual savannah is overlaid on a school field, and children have to cooperate as "lions" to hunt the savannah for virtual prey.

Both applications are successful demonstrations of a playful approach to learning. In contrast with the focus of the research presented here, these applications involve a structured and externally motivated educational activity rather than a game that is designed to be played purely for fun and more than once.

Looking at pervasive games, we note the reliance either on location bound infrastructure, e.g., placing the devices in the forest for Ambient Wood, or accessing virtual content indexed by physical location, e.g., using GPS for location awareness. However, GPS errors can adversely influence the game play [8], and using location awareness does not automatically lead to better game performance [5]. Without excluding location awareness, it appears that it would be fruitful to explore alternative mechanisms to support interaction between players and game content.

The brief overview above shows that the topic of pervasive games for children is still underexplored. Addressing this gap, we introduce a new genre of pervasive games targeting children. These games are especially suited for late childhood (6-11) when children are able to follow game rules. The focus on outdoor play also brings about the need for interaction mechanisms more consistent with outdoor children's play. To emphasize the difference between traditional pervasive games running on handheld devices which force players to "look down" the envisioned games are called "Head Up Games" (HUGs) [10]. Our aspiration is to combine benefits of modern pervasive technology with the advantages of traditional outdoor play.

As such, HUGs are a subset of pervasive games; they are played by co-located players in the physical world taking advantage of pervasive technology. In the following section, we unpack the concept, compare it to related developments in the broader research field, and discuss experiences gained from the design, development, and evaluation of several HUGs for children. This article concludes with reflections on this vision and directions for future research.

\section{Head Up Games}

In the "old" days, before the introduction of technology, entertainment for children was fairly straightforward. A child played with toys, or with other children. A good example of the types of games played is nicely depicted in a painting of Brueghel (Fig. 1). Many of the games

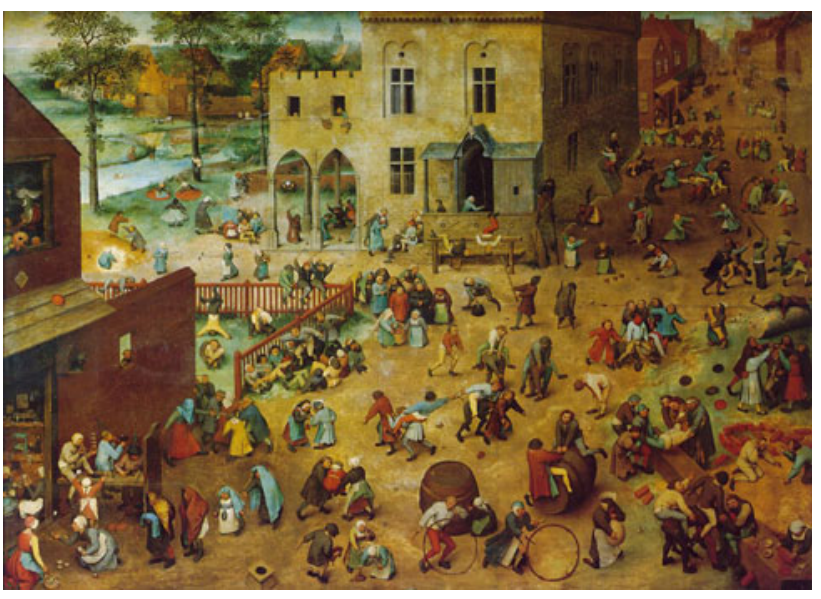

Fig. 1 Children's Games by P. Brueghel, sixteenth century [34]

illustrated are still popular today, like tag, hide-and-seek, and ball games.

These games have a few characteristics in common; they require physical activity, and are played with few basic materials that children can easily take along (like a ball, a hoop, or a skipping cord). As these games are played with multiple players in the same physical space, these games are rich in social interaction. Finally, the rules are often few and simple, appropriated and adapted by players. For the remainder of this article, we will refer to this type of games as traditional (outdoor) games.

If Brueghel were to paint his picture again nowadays, it would probably be more like Fig. 2. Compared to previous generations, many children do not spend much time playing out of doors, at least in industrialized societies [6, p. 168]. Children are spending an increasing amount of time indoors for less active and solitary pastimes, e.g., watching television, surfing the internet, or playing games on consoles [11].

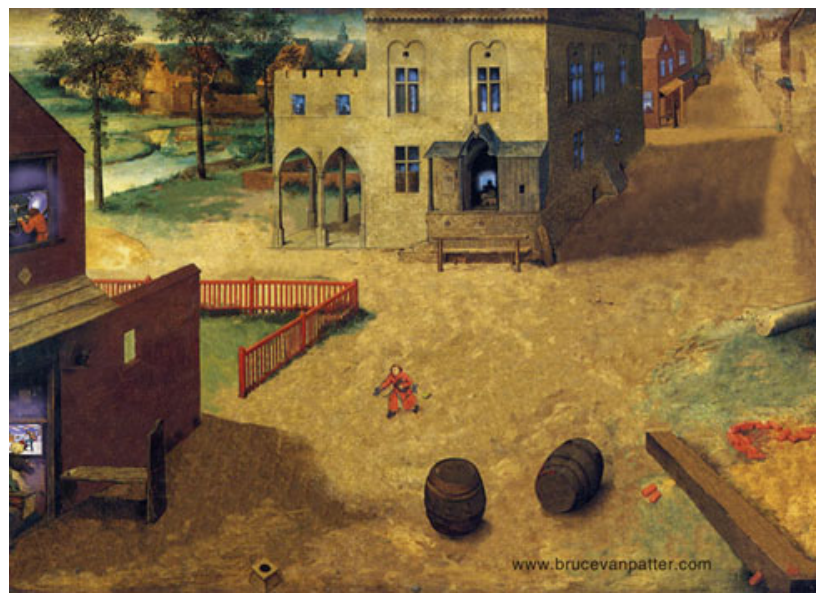

Fig. 2 Adaptation of Brueghel's Children's Games, by Bruce van Patter [35] 
Child development theories acknowledge that play has an important role in a child's development [6, 7]. For example, make-believe play helps form abstract thinking, and playing with other children leads to development of social skills. So, spending more of their time engaged in solitary activities can deprive children of developmentally valuable experiences. Some theorists even go as far as claiming that without "backyard" play typical for previous generations, children are in danger of not developing morally [6, p. 168]. Although it can be reasoned that internet provides a medium for forming and maintaining social relationships, concerns have been voiced about the depth and quality of these relationships, and how they compare to offline social relationships [13, 14].

We argue it is possible to combine the appeal of indoor digital games with the benefits of traditional outdoor play, thereby creating rich gaming experiences for children. Paraphrasing Marzano's maxim in "La Casa Prossima Futura" [15], the vision of HUG can be put forward as "the games of tomorrow will look more like the games of yesterday than the games of today". Our aim is to create:

outdoor, co-located, multiplayer pervasive games that encourage social interaction, stimulate physical activity and support adaptable rules, creating a fun experience.

\subsection{Social interaction}

A game can provide the venue for a range of social interactions to unfold, e.g., competition, cooperation, negotiation, etc. While in many multi-player computer games social interaction is possible, it is typically limited to online chat or other forms of mediated communication. A position maintained by media theorists is the superiority of face-toface communication over mediated interactions in its ability to convey non-verbal cues and, more fundamentally, the subtleties of verbal and non-verbal communication [16]. HUGs, like traditional games, should take the advantage of the co-presence of players in the playing field, and should encourage a broader range of social interactions.

\subsection{Physical activity}

Playing traditional outdoor games often involves physical activity. As an input to the design of Camelot [17], observations and interviews regarding what makes outdoor play fun for children showed that children favor games that are rich in physical activity.

\subsection{Flexible and adaptable rules}

Children engage in games with rules especially during late childhood (ages 6-11) [6, p. 73]. Traditional games often have flexible rules, e.g., a game of chase can be played two against two, but is equally playable in two teams of seven, or seven against one which makes them playable in different contexts. Winning and losing rules do not have to be set in stone, but are negotiated: "once you are caught you are out", or, "once caught you can be set free by a team mate". Specifically around the age of 10-11, children enjoy adapting game rules making rules increasingly complex and precise through a process of negotiation. Addressing the preferences and abilities of different children, the available resources, adhering to game rules, ensuring fairness in the play are important elements of their socialization process [6, p. 79].

\subsection{Fun}

Many pervasive games for children pursue an educational goal (e.g., [9]), often resulting in a game with a narrative designed to transfer knowledge about a certain topic. Although these games can be a fun experience too, typically they can only be played once, since then the knowledge has been learned. We aim at creating games that are primarily aimed at having a fun experience, that children ideally will keep returning to, in a similar way that children keep playing games like tag and hide-and-seek.

With the above in mind, consequences with respect to technological choices for HUGs can be outlined. First, in contrast with other pervasive games HUGs should make minimal use of screen-based technology, since this can compete with the ability to interact directly with other players. A typical image for these games is of players attending to their devices 'head down' and attempting to observe and act within a virtual world through a handheld device. While interesting and engaging experiences are thus achieved, this form of interaction diminishes opportunities for direct face-to-face social interactions between players. Another drawback of a screen-based interaction with the game world is that it does not go together well with running around.

We place less emphasis on creating a virtual game world and meshing it with the physical world, focusing mostly on supporting the game play. Vygotsky [7] has argued how make-believe play has a crucial developmental function to free thought from perception. The reliance of current game technology on explicit audio and visual effects competes with children's use of their own imagination. Instead, we argue to employ a richer foray of interaction styles with the game and research alternative possibilities such as the use 
of sensors to sense for example motion, contact, or proximity.

Furthermore, whereas location bound infrastructure or bulky technology restricts portability, traditional games can be played in any space that is appropriately large and safe; all that is needed are the players, knowledge of the rules, and perhaps some simple game objects. An ideal to aim for is to assume as little as possible regarding the pervasive technology infrastructure required (e.g., do not assume GPS coverage or Wi-Fi connectivity).

\section{Head Up Games and related concepts}

Some of the characteristics of HUGs are also found also in related genres of interactive applications and games.

Exertion interfaces [18] are applications that motivate people to do sports activities where remote players compete in physically exhausting games. Activity monitoring and health coaching applications aim to motivate people to increase physical activity. The mobile phone application 'Houston' [19] creates awareness of the user's own activity level and lets the users share their activity information with friends. Sensing general activity level and using this within a game has been demonstrated in a series of games described as Neat-O-Games [20] and has even been applied in a commercial context for the Nintendo DS platform.

Whereas exertion interfaces have focused on adult players, research in Intelligent Playgrounds examines the use of intelligent objects and environments, to create a stimulating playground for children. Lund et al. [21] present building blocks ('tangible tiles') that are reconfigurable into different games that detect and respond to the children's movements. Seitinger et al. [22] describe how an interactive pathway impacts children's play patterns in outdoor playgrounds. They observed that many different play patterns emerged from a simple design that allowed for open-ended play. The interactive slide [23] is a compelling application that is a mix between exertion interfaces and intelligent playgrounds aiming for co-located, collaborative, and physically active play.

Bekker et al. [24] present the concept of intelligent products for open-ended play. In open-ended play, no fixed game structure is offered; instead, the intelligent toys provide a setting where children are free to create their own games. Given their interest to support play and physical activity, the games considered by Bekker et al. bear many similarities with HUGs. However, a HUG is not openended. Open ended play does not include game rules. From a player's perspective, the distinction is best described by Salen and Zimmerman when discussing the "Magic Circle" of play [25, p. 95] "...with a toy it may be difficult to say exactly when the play begins and ends. But with a game, the activity is richly formalized. The game has a beginning, a middle, and a quantifiable outcome at the end....Either the children are playing Tic-Tac-Toe or not." HUGs promote flexibility of game rules and players develop game rules of their own, but assume that game rules are implemented at least partially.

To conclude, we mention related work in the area of Social Games, i.e., games that have been specifically designed for enhancing social interaction. The game pOwerball [26] is a mixed reality tabletop game that resembles a pinball game. Two to four players have to collaborate to free imprisoned creatures. It was designed to encourage social interaction between children with and without a physical learning ability. Cheok et al. [27] present 'Capture the flag', a mixed reality social game on smart phones. The game is played in teams of real-world and virtual-world players who communicated through textmessaging. In contrast to this example, HUGs are different, as they are played co-located, which also makes communication via game devices superfluous.

One can question whether a neologism is needed to describe the type of games we are designing. In the review of related genres of games, we have shown how the defining characteristics of HUG render them distinct from other genres, so at least the term has a clear semantics. The distinct meaning though is not the primary reason for introducing the term; rather our aim is to take a clear position on the priorities designers and researchers should be setting when designing games for children.

\section{Experiences with the design of Head Up Games}

So far, several games based on the HUGs concept have been developed, starting with Camelot in 2006, followed by Stop the Bomb in 2007. In 2008 we further developed Stop the Bomb and renamed it Save the Safe, and around the same time the game HeartBeat was created. This section discusses Camelot, Save the Safe, and HeartBeat, and reflects shortly on our experiences designing and evaluating these games.

\subsection{Overview}

All games have been developed in an iterative and usercentered way, meaning that during the design process, we regularly let users play with prototypes of the game, and used the users comments as input for the next iteration of the game. In each case, the design concluded with a summative evaluation to see how the intended design goals were met. For reference, Table 1 provides a short overview of some parameters of these summative evaluations. 
Table 1 Overview of evaluation parameters

\begin{tabular}{llll}
\hline & Camelot & $\begin{array}{l}\text { Save the } \\
\text { Safe }\end{array}$ & HeartBeat \\
\hline No of participants & 10 & 27 & 32 \\
Age participants & $7-10$ & $8-9$ & $11-13$ \\
$\begin{array}{l}\text { Duration (min per game) } \\
\text { No of participants (per }\end{array}$ & $8-9$ & $3-4$ & $4-5$ \\
game) & 4 & 8 & 8 \\
$\begin{array}{l}\text { Sessions played (per pp) } \\
\text { Evaluation methods }\end{array}$ & 2 & 3 & 2 \\
& $\begin{array}{l}\text { Unstructured } \\
\text { observation, } \\
\text { group interviews }\end{array}$ & $\begin{array}{l}\text { Structured observation, } \\
\text { rankings, group } \\
\text { interviews }\end{array}$ & $\begin{array}{c}\text { Structured observations, } \\
\text { rankings, group } \\
\text { interviews }\end{array}$ \\
\hline
\end{tabular}
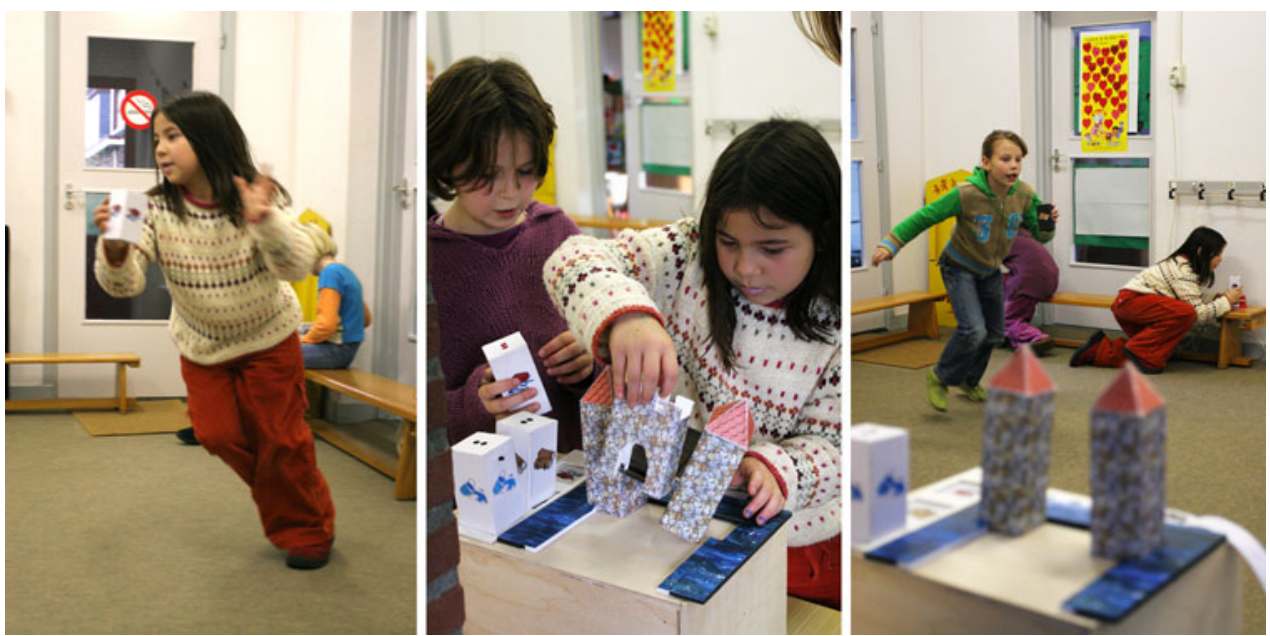

Fig. 3 Left and right: Players running after acquiring resources. Middle: building the castle at the castle construction site

\subsection{Camelot}

In Camelot [17, 28], children compete in two teams to build a castle (see Fig. 3). To this end, the teams have to gather different types of resources that are spread around in zones on the play field. The first team to complete building their castle wins the game. The game is subdivided in four phases. In each phase, a different part of the castle needs to be built, and each part requires a different combination of resources to be collected. Players can store a limited amount of resources at the castle construction site, for use in a later phase, but players are also allowed to trade resources. Randomly during the game, a ghost appears and tries to steal resources from the teams.

No screen displays are used in Camelot. Instead, small dedicated devices (collectors and zones) have been designed to support players acquire resources (see Fig. 4), to store them and to exchange them. The devices are implemented using PIC microcontrollers supporting the game logic, connected to infrared technology for communication between devices and LED lights to provide feedback to players. Each device functions as a stand- alone unit; hence, there is no need for centralized computer control. The collectors weigh very little, so children can easily carry them while running around. The zones are small and portable, so the game can be played anywhere.

Camelot involves several social interactions: competition, cooperation, discussion of tactics, and team play. Evaluations involving play testing, revealed that fun was derived from the social interaction, the competition between the teams but also the suspense added by the unpredictable appearance of the ghost.

With Camelot, we demonstrated the potential of supporting pervasive games using other technologies than screen technologies and how fairly 'simple' technologies, can provide novel and enjoyable play experiences.

The nature of play supported by Camelot was well balanced. Intense physical activity alternated with periods of rest in such a way that Camelot did not resemble a dedicated sports application; something children appreciated during the evaluation sessions.

The suspense added by the appearance of the ghost was largely enjoyed by children. This led us to consider the 
Fig. 4 Left: Players charging their collectors at the zones. Right: Resource zone (above) and collector (below)

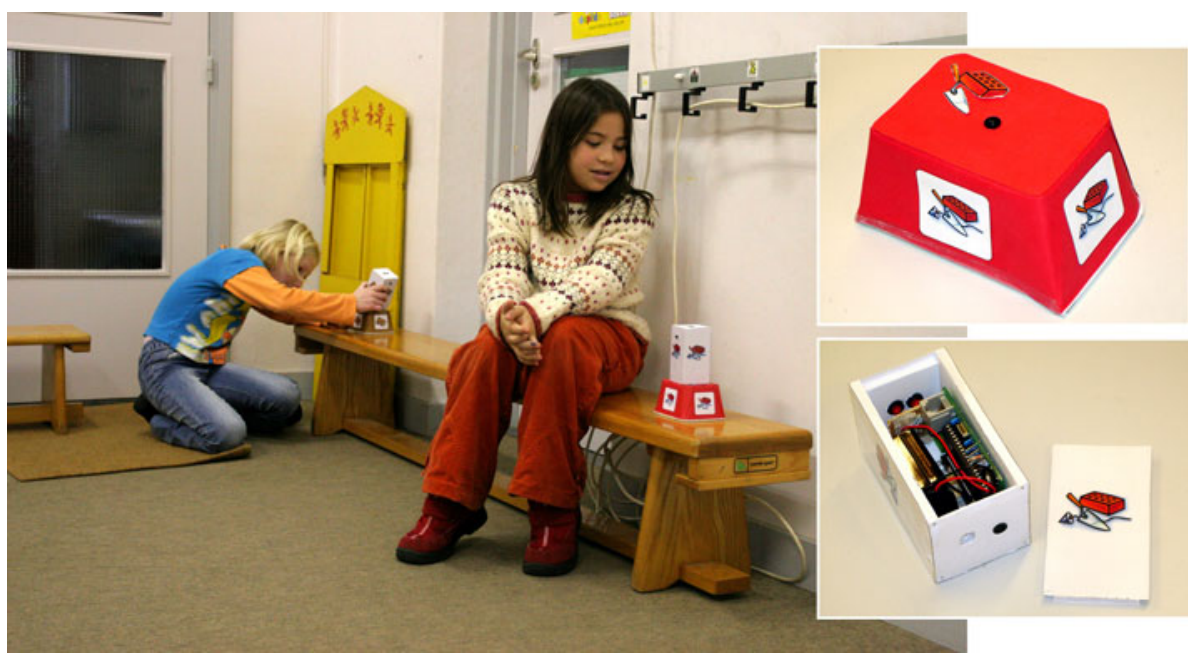

introduction of virtual elements in HUGs and to examine their role more systematically in the next HUG designs.

\subsection{Save the safe}

Save the Safe [29] was developed based on the game Stop the Bomb [30], since the latter game had not been fully developed. Save the Safe revolves around obtaining (or guarding) a key to break into (or protect) a safe. The players are divided into a team of guards and a team of burglars; the guards win when they successfully guard the key from the burglars for the duration of the game. The burglars win the game when they steal the key from the guards and unlock the safe.

Each player wears a belt (see Fig. 5). Mounted on the belts are a few LEDs and embedded in the belts are a vibration motor and a communication unit. At startup, the units automatically form an ad hoc network. The communication unit is not meant for communication between players, but is used for determining distances between players, by measuring the signal strength of nearby belts.

At the start of the game, the belt shows the color of each player's team. Besides serving as an indication of the player's team, the belts also indicate by vibration possession of the virtual key. If a player possesses the key, his belt starts vibrating while other players receive no such feedback. If another player approaches the key-bearer sufficiently close, the key is automatically transferred to this other player's belt. At the start of the game, the team roles are randomly assigned to players and the key is initially given to the guards.

In the final summative evaluation, we compared two versions of the game, one using a virtual key and one using a physical key. Our aim was to evaluate how the physicality of game objects affected game play.

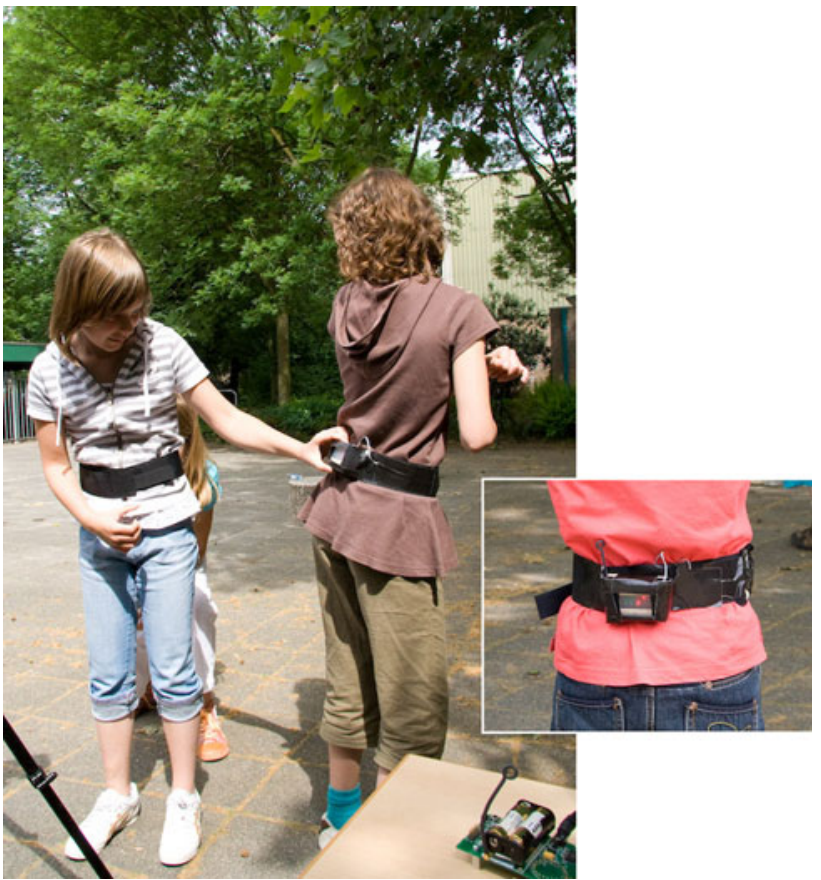

Fig. 5 Players checking each other's team colors. Inset: belt

Save the Safe is a high paced game verging on a sports game, albeit one supported by pervasive technology; this was especially true, when a physical ball was used to represent the key. Surveying participants' experiences showed how the games were more appealing to physically inclined players and, by the same token, less suitable for players who enjoy applying tactics in a game. Concerning social interaction, since the game was high paced, there was less time to discuss team tactics in depth. However, we did observe many yells and encouragements for other team mates.

With respect to using a virtual or a physical game object, it turns out that, interestingly, both approaches have their 
merit: a physical game object acts as a shared representation for all players, draws the attention of players and facilitates them to coordinate their actions. A virtual game object, when designed well, can lead to higher uncertainty, suspense, and higher intensity activity.

\subsection{HeartBeat}

HeartBeat (initially developed as TreasureHunter) [31] was designed to explore the possibility of using biofeedback in HUGs. HeartBeat can be described as an adaptation of Capture the Flag combined with elements of Tag and Hide-and-Seek. Players are randomly divided into a defending team and an attacking team. One of the defenders is in possession of a virtual treasure and, for the defending team to win, needs to remain untagged by an attacker for the duration of the game. The attacking team wins when they tag the defender with the virtual treasure and thereby capture the treasure. So, during the game, the attackers need to hunt down defenders and tag them. Once tagged, a defender must join the attacking team. Defenders can protect the player with the treasure; when a defender has teamed up with the player with the treasure, both are protected against a single attacker.

Small portable devices support game play (see Fig. 6): each player has one and at the start of the game, the devices randomly assign players to either the defending team or the attacking team. After tagging, a change of team is effected by docking the attacker device to that of the defender. Using the same interaction technique, the virtual treasure can be passed on between defenders.

Biofeedback is incorporated in the game using players' heart rate as input. Each player wears a heart rate sensor and during the game a player's heart rate is monitored. If the heart rate exceeds a preset value, the player's device starts broadcasting the heart rate to nearby devices of the

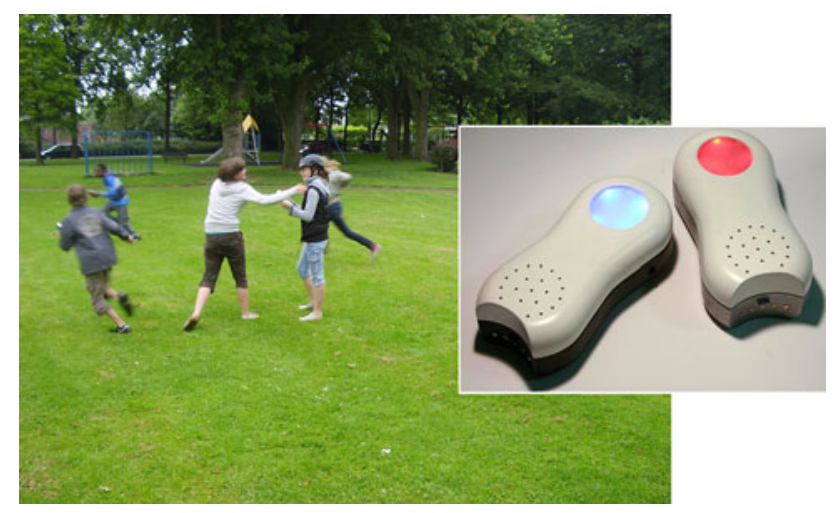

Fig. 6 Children playing HeartBeat (left) and HeartBeat game devices, showing team colors (right) opposing team, letting them know that opponents are near. So, besides running away from attackers, players can avoid being found either by hiding in bushes to stay out of sight physically or striving to keep down their heart rate to remain 'hidden' virtually. The tension between these tactics adds interest and suspense to the game play.

From the evaluation of HeartBeat, we learned that compared to Save the Safe, HeartBeat is a more mixed paced game, combining both running and hiding in a large area. Children related very well to the idea of gaming outdoors in a technological enhanced way. Heart rate sensing was very novel for the children and had a seemingly positive influence on the game, although evaluation results were not unequivocal.

\section{Lessons learned}

In this section, we report our lessons learned while designing and evaluating several HUGs.

This section is split up in three parts: first, we reflect upon the goals for HUGs, and in how far we have been able to incorporate them in our designs. Second, we will focus on lessons learned during the design process of HUGs, and how technology is interweaved in that process. Finally, we discuss issues that arise relating to user evaluations.

\subsection{Characteristics of HUGs}

First, an important word of caution is noted: it is deceptively easy to design a HUG that children will have fun with. This is especially the case when we evaluate whether or not they have fun in a single evaluation session. This is true for children's games in general; the evaluation of a game is typically (or it should be) set up as a pleasant activity in which children play a central role [28]. Achieving continued success and motivating children to return to a game is harder. Children return to traditional games when they have a need for the physical activity and the social interaction that these games support. On the other hand, they tend to return to computer games to enjoy the evolving challenges that these games provide, the variation on the audiovisual elements or the fantasy elements supported by a game narrative [6, Chap. 6]. In the reported examples of HUGs, the latter aspects that are traditionally found in gaming are still not sufficiently developed. To ensure long term success, more effort needs to be spent into developing reward structures, leveling, and generally motivating children to return to the game.

The idea of encouraging social interaction has been a long standing aim for research in games for children, prior to the emergence of HUGs (see survey of related work in earlier sections). Iterative design of these games and 
especially of the ones presented has been found, without exceptions, successful in encouraging social interactions. Besides this and of engendering social interactions as found in traditional forms of play, the goal of social gaming has remained very loosely defined. It is necessary for researchers working in this field to become more specific about the forms of social interactions that games should encourage and perhaps about the developmental benefits that such games are expected to offer. Such specificity could help move this research field further from developing well-motivated games to delivering concrete benefits to players. Hendrix et al. [32] present an example of this more focused approach to supporting the development of social skills in children.

Encouraging physical activity was quite an easy task from a design perspective. Players could be motivated to be active in several ways, either directly setting them the challenge to escape or catch an opponent or, more subtly, by creating a tension between the need to run and the need to develop tactics that would allow a player to remain invisible (e.g., in HeartBeat). Whereas the effect during a game may be directly quantified by an observation scheme like OPOS [12], this is only the part of the picture. Achieving the highest degree of physical activity would equate a game to sports, it could be played until the children are exhausted and then abandoned. Concrete benefits regarding a less sedentary lifestyle for children can only be evaluated in the long term. Games like the ones described above can have a positive effect, if children choose to play these rather than be inactive in the playground or even playing these games as opposed to other handheld computer games.

In setting out to design and develop HUGs, an important tenet was to avoid screen-based interaction. This choice has paid off, as we have shown that it is possible to design engaging game experiences without screen technology, but retrospectively seems somewhat extreme. Screens allow rich feedback and efficient information exchange so they could have a useful role in a HUG as long as they do not command the player's sustained and concentrated attention. Rather than avoiding screens at all costs, the development of HUGs should proceed to explore novel interaction styles fitting for the playground. The interactions shown in these games go beyond those traditionally used in augmented reality and tangible user interfaces like 'pick and drop', or 'selection' of virtual entities. Physical objects are used as containers of resources that can be passed from player to player by contact (Camelot), resources, and game objects are separated to those that are movable by players and those that are bound to one location (Camelot), players can interact with each other by proximity (HeartBeat, Save the Safe), and may own properties unknown to them but made observable through the devices to other players (Save the Safe, HeartBeat). The list continues, but it is clear that developing novel and new interaction styles can spawn novel and exciting game experiences.

So far, the ambition to have flexible and adaptable rules has received little attention in our designs. As can be expected of research prototypes, only part of the game rules were implemented in the technology. We did notice though, that in all the evaluations discussed and in the various phases of the design process children or even adult test participants would tend to modify those game rules that the technology did not enforce. This could be for a variety of reasons, for example, to make the game more exciting, or to balance unequal abilities of players. There is nothing unusual about this behavior neither is it surprising that players tend to look for ways to cheat the technology once they know how it works [25, 33]. Where technology can provide an interesting contribution to this process of adaptation and appropriation, is when changes in the implemented game rules can be effected by users and eventually maintained for future occasions or shared between players. The research challenge that emerges in the development of HUGs is the consideration of games as content created, shared, and modified by communities of players.

\subsection{Game design and technology}

As the emphasis is on outdoor play, an obvious way to design HUGs is by augmenting traditional outdoor games with technology. This augmentation can support different aims: to enforce rules and facilitate logistics or to provide new and engaging sensorial experiences through technology. The downside of this approach is that the added value of the technology is then rather limited, provided the games are already played by children; technology can be just 'sugaring' added on top of the traditional game, but not an essential aspect of game play.

Another approach, which we followed with the design of Camelot and to an extent with the design of Stop the Bomb and Save the Safe is to start with a lo-fi prototype, play test it fast and gradually introduce technology. This approach is consistent with traditional rapid prototyping approaches for interaction design and with traditional game design methods [25].

We discovered in practice that this approach can lead to problems. While the focus on fast iteration and on play testing were found indeed beneficial to the designed games, we also experienced that first making a game that is truly playable in its low-tech version and only then introducing technology can bring about the problems mentioned above regarding the augmentation of traditional games; the added value of the technology is again marginal and design 
opportunities can be overlooked. In the design of Heartbeat, we sought to introduce technology early on and to explore the relevant design space. This design approach can lead to better integration and use of technology, making games designs that are not playable without the introduction of technology. Time-outs, biofeedback, random allocation of teams, proximity sensing, actions that are concealed from other players, balancing difficulty with randomness are some of the possibilities technology offers that could be poorly utilized if an already playable game is augmented.

Furthermore, technology offers the opportunity to add virtual game objects, characters, or properties to the game that are not visible to all players but felt or heard by only a few. From the game evaluations, we conclude that these elements can add to the suspense of the game.

We underline that it is not necessary (or even feasible) to capture all rules in technology. Many rules are automatically enforced by players themselves. For example, we considered to detect with technology who was tagged (initially, there was a rule in Camelot that required tagging, but was later dropped from the final version); however, we soon reconsidered this notion. First, because the required technology would be complicated to implement, and second, it turned out that for players themselves it is perfectly clear when one is tagged or not.

Designing game rules for outdoor play where players are co-located has several differences to designing computer games. While in the design process, designers can make use of the aforementioned tendency by players to make their own rules, extending and modifying existing ones. During play-testing sessions the designer can deliberately provide only a small and loose set of rules. In trying to understand this rule set players are bound to adapt them, fill-in gaps, resolve ambiguities, and remove game-stoppers. Subsequently, the resulting set of new rules can be used in the next iteration of development.

\subsection{Game evaluation}

Considerable attention has been spent on play-testing the games. Play-testing outdoors with groups of children presented many challenges, and this lead to several innovations with regards to evaluation methodology.

The evaluation of Camelot and of Stop the Bomb included observations of children playing the game; these observations focused on physical activity and social interaction, showing that anticipated behaviors were indeed manifested. However, the observations were unstructured making it difficult to draw fine comparisons and to deduce how game design decisions affected different aspects of play. To obtain this deeper insight into play and how design decisions affect game play the Outdoor Play
Observation Scheme [12] was developed to support structured observation. The scheme includes codes for describing social interaction, physical activity, and focus of attention.

Furthermore, we employed head-mounted cameras to record video footage from players dispersed in the woods $[29,31]$, since stationary cameras were not sufficient to capture all game play. While footage from a player's perspective is thus possible to capture, the results so far have been somewhat less than expected. Helmets sometimes slipped off backwards, resulting in footage of foliage and blue skies or interfered with playing the game.

Finally, the fun toolkit survey was tailored for group interviews [29], as it was unfeasible to interview each participant separately. Asking children to decide together on a shared ranking of elements of the game regarding fun, or some other aspect that interests the evaluator, can prompt discussions of children and let them verbalize opinions and feelings in a natural way.

\section{Conclusion}

This article has summarized the development of a novel genre of outdoor pervasive games for children that are collectively described as HUGs. HUGs have some defining characteristics that set them apart from other pervasive games; they encourage physical activity while steering clear from being a sport game, they support rich social interaction face-to-face by co-located players while avoiding to transpose them into a virtual world or to focus their attention on game content and away from the other players, and they rely on simple adaptable rules that can be modified by players.

So far a few games have been developed that have these general characteristics; the three most instructive examples were discussed. Experiences gained from their evaluation show that the original ambitions have been met to a large degree. Still, the overarching goal of bringing the elements of computer gaming outdoors has been met only partially. Future research needs to explore richer sensory experiences, fantasy elements, and reward structures suitable for HUGs in order to motivate sustained engagement with the game. Finally, the scene is set for attracting players to engage with these games repeatedly and for allowing children to be put into the role of game content creators.

Acknowledgments This research has been carried out as part of the IST FET project PASION, (IST 027654). We wish to thank students and colleagues who have participated in different aspects of this research programme: Janneke Verhaegh, Angelique Kessels, Saskia Bakker, Yang Guo, Koen Hendrix, Dirk v.d. Mortel, Tim Tijs. We thank Tilde Bekker for suggesting reference to P. Breugel's painting. 
Open Access This article is distributed under the terms of the Creative Commons Attribution Noncommercial License which permits any noncommercial use, distribution, and reproduction in any medium, provided the original author(s) and source are credited.

\section{References}

1. Magerkurth C, Cheok AD, Mandryk RL, Nilsen T (2005) Pervasive games: bringing computer entertainment back to the real world. Comput Entertain 3(3):4

2. Nieuwdorp E (2007) The pervasive discourse: an analysis. Comput Entertain 5(2): 13

3. Benford S, Anastasi R, Flintham M et al (2003) Coping with uncertainty in a location-based game. Pervasive Comput, IEEE 2(3):34-41

4. Benford S, Crabtree A, Flintham M et al (2006) Can you see me now? ACM Trans Comput-Hum Interact 13(1):100-133

5. Nova N, Girardin F, Molinari G, Dillenbourg P (2006) The underwhelming effects of automatic location-awareness on collaboration in a pervasive game. International conference on cooperative systems design, COOP 2006, pp 224-238

6. Scarlett WG, Naudeau SC, Salonius-Pasternak D, Ponte IC (2004) Children's play. Sage Publications, Inc., Thousand Oaks

7. Vygotsky L (1976) Play and its role in the mental development of the child. In: Bruner JS, Jolly A, Sylva K (eds) Play: its role in development and evolution. Basic Books, New York

8. Benford S, Rowland D, Flintham M et al (2005) Life on the edge: supporting collaboration in location-based experiences. Proceedings of CHI' 05, ACM, pp 721-730

9. Rogers Y, Price S, Fitzpatrick G et al (2004) Ambient wood: designing new forms of digital augmentation for learning outdoors. Proceedings of IDC'04, ACM, pp 3-10

10. Soute I, Markopoulos P (2007) Head up games: the games of the future will look more like the games of the past. In: HumanComputer Interaction, INTERACT 2007, pp 404-407

11. Curtis $P$ (2009) Internet generation leave parents behind. The guardian.

http://www.guardian.co.uk/media/2009/jan/19/internetgeneration-parents

12. Bakker S, Markopoulos P, Kort YD (2008) OPOS: an observation scheme for evaluating head-up play. Proceedings of NordiCHI'08, ACM, pp 33-42

13. Cummings JN, Butler B, Kraut R (2002) The quality of online social relationships. Commun ACM 45(7):103-108

14. Hellenga K (2002) Social space, the final frontier: adolescents on the Internet. In: Mortimer JT and Larson RW (eds) The changing adolescent experience: societal trends and the transition to adulthood. Cambridge University Press, Cambridge, pp 208-249

15. Marzano S (2008) Ambient culture. In: Encarnação J, Aarts E (eds) True visions: the emergence of ambient intelligence. Springer, Berlin

16. Short J, Williams E, Christie B (1976) The social psychology of telecommunications. Wiley, New York

17. Verhaegh J, Soute I, Kessels A, Markopoulos P (2006) On the design of Camelot, an outdoor game for children. Proceedings of the 2006 conference on Interaction design and children, ACM, pp $9-16$
18. Mueller F, Stevens G, Thorogood A, O’Brien S, Wulf V (2007) Sports over a distance. Pers Ubiquit Comput 11(8):633-645

19. Consolvo S, Everitt K, Smith I, Landay JA (2006) Design requirements for technologies that encourage physical activity. Proceedings of the SIGCHI conference on human factors in computing systems, ACM, pp 457-466

20. Fujiki Y, Kazakos K, Puri C, Pavlidis I, Starren J, Levine J (2007) NEAT-o-games: ubiquitous activity-based gaming. CHI'07 extended abstracts on human factors in computing systems, ACM, pp 2369-2374

21. Lund HH, Klitbo T, Jessen C (2005) Playware technology for physically activating play. Artif Life Robot 9(4):165-174

22. Seitinger S, Sylvan E, Zuckerman O, Popovic M, Zuckerman O (2006) A new playground experience: going digital? CHI'06 extended abstracts on Human factors in computing systems, ACM, pp 303-308

23. Soler-Adillon J, Parés N (2009) Interactive slide: an interactive playground to promote physical activity and socialization of children. Proceedings of the 27th international conference extended abstracts on Human factors in computing systems, ACM, pp 2407-2416

24. Bekker T, Sturm J, Wesselink R, Groenendaal B, Eggen B (2008) Interactive play objects and the effects of open-ended play on social interaction and fun. Proceedings of the 2008 international conference in advances on computer entertainment technology, ACM, pp 389-392

25. Salen K, Zimmerman E (2003) Rules of play: game design fundamentals. The MIT Press, Cambridge

26. Brederode B, Markopoulos P, Gielen M, Vermeeren A, Ridder HD (2005) pOwerball: the design of a novel mixed-reality game for children with mixed abilities. Proceedings of the 2005 conference on Interaction design and children, ACM, pp 32-39

27. Cheok A, Sreekumar A, Lei C, Thang L (2006) Capture the flag: mixed-reality social gaming with smart phones. Pervasive Comput, IEEE 5(2):62-69

28. Markopoulos P, Read JC, Macfarlane S, Höysniemi J (2008) Evaluating children's interactive products: principles and practices for interaction designers. Morgan Kaufmann, San Francisco

29. Soute I, Markopoulos P (2009) Evaluating the effect of the tangibility of game elements on physical activity and social interaction in head up games. CHI'09 extended abstracts on human factors in computing systems

30. Hendrix K, Yang G, van de Mortel D, Tijs T, Markopoulos P (2008) Designing a head-up game for children. Proceedings of the HCI ' 08 conference on people and computers XXII, pp 45-53

31. Magielse R, Markopoulos P (2009) HeartBeat: an outdoor pervasive game for children. Proceedings of the 27th international conference on human factors in computing systems, ACM, pp 2181-2184

32. Hendrix K, Herk RV, Verhaegh J, Markopoulos P (2009) Increasing children's social competence through games, an exploratory study. Proceedings of the 8th international conference on interaction design and children, ACM, pp 182-185

33. Consalvo M (2007) Cheating: gaining advantage in videogames. The MIT Press, Cambridge

34. Bruegel P (1560) Children's Games. http://www.gamesmuseum. uwaterloo.ca/VirtualExhibits/Brueghel/aboutpaint.html

35. van Patter B Adaption of Peter Brueghel's Children's Games. http://www.brucevanpatter.com/brueghel_painting.html\# 